\title{
3-Normeridamycin: A Potent Non-Immunosuppressive Immunophilin Ligand is Neuroprotective in Dopaminergic Neurons
}

\author{
Mia Y. Summers, Margaret Leighton, Danni Liu, Kevin Pong, Edmund I. Graziani
}

Received: February 14, 2006 / Accepted: March 8, 2006

(C) Japan Antibiotics Research Association

\begin{abstract}
Normeridamycin (1), isolated from fermentation extracts of the soil actinomycete Streptomyces sp. LL-C31037, demonstrated potent neuroprotective activity. When challenged with the neurotoxin 1-methyl-4phenylpyridinium $\left(\mathrm{MPP}^{+}\right)$, known to induce parkinsonism, 1 restored functional dopamine uptake in a concentrationdependent manner, with an $\mathrm{EC}_{50}$ of $110 \mathrm{nM}$ in dopaminergic neurons. The structure of $\mathbf{1}$ was determined via spectroscopic methods, and the immunosuppressive and immunophilin binding properties of the compound were also measured.
\end{abstract}

Keywords immunophilin ligand, neurodegeneration, neuroprotection, Parkinson's disease, structure determination

\section{Introduction}

Therapeutic agents that slow or reverse the effects of neurodegenerative diseases such as Parkinson's disease (PD) would fulfill a major and as yet unmet medical need. In an effort to expand upon the reported neuroprotective and neuroregenerative effects of natural product immunophilin ligands such as FK506 and rapamycin we herein report the isolation, characterization, and preliminary in vitro biological activity of a new compound, 3-normeridamycin (1), obtained from fermentation extracts

E. I. Graziani (Corresponding author), M. Y. Summers, M. Leighton: Department of Chemical \& Screening Sciences, Wyeth Research, 401 N. Middletown Rd., Pearl River NY 10965, U.S.A. E-mail: graziaei@wyeth.com

D. Liu, K. Pong: Department of Neuroscience Discovery Research, Wyeth Research, CN8000, Princeton NJ 08543, U.S.A. of the soil actinomycete Streptomyces sp. LL-C31037.

$\mathrm{PD}$ is a progressive neurodegenerative disease characterized by the selective degeneration of dopaminergic (DAergic) neurons of the substantia nigra. Current PD medications treat symptoms, whereas none prevent or retard DAergic neuron degeneration [1]. However, a number of clinical trials evaluating neuroprotective agents are in progress [2]. Immunophilins are proteins with cis-/trans-proline isomerase enzymatic activity that act as receptors for immunosuppressant drugs. More specifically, rapamycin (2) and FK506 (3) bind to the immunophilin FK506-binding-protein-12 (FKBP12). The immunophilin-3 complex then binds to calcineurin to inhibit cell proliferation, while in contrast, the immunophilin-2 complex binds to mammalian targetof-rapamycin (mTOR) to induce cell cycle arrest [3]. Studies indicate immunophilins are expressed 10 50 fold more highly in central nervous system (CNS) and peripheral nervous system (PNS) tissue than in immune tissue [4]. These findings prompted the evaluation of immunosuppressive immunophilin ligands on nervous system tissue [5]. Subsequent studies, spanning the last decade, revealed potent neuroprotective and neuroregenerative properties of immunophilin ligands in both culture and animal models [6]. However, the mechanisms underlying these trophic effects are still largely unknown, though the role of FKBP52 has been implicated in a number of studies [7].

In the course of screening microbial extracts for biological activity, the actinomycete designated as LLC31037 was identified as producing a compound having FKBP12 binding activity, as well as neuroprotective activity. 


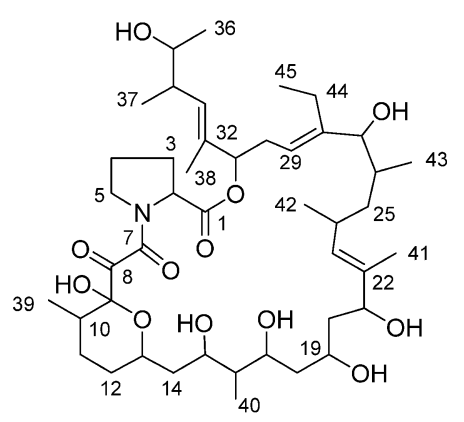

1

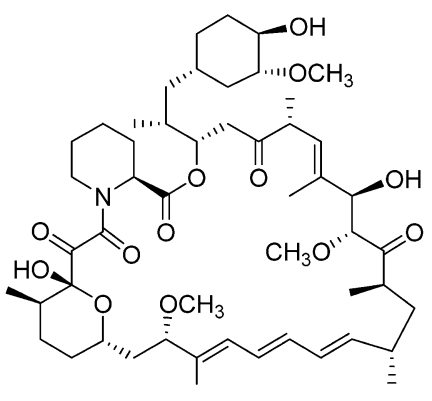

2

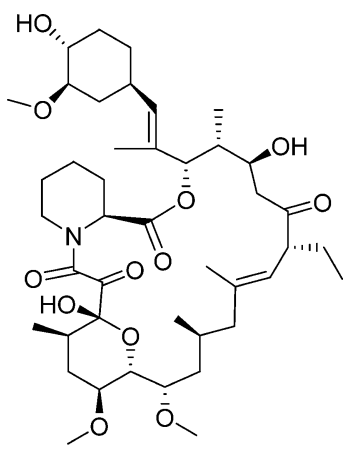

3

Fig. 1 Structures of 3-normeridamycin (1), rapamycin (2), and FK506 (3).

\section{Materials and Methods}

\section{General}

HPLC was performed on a Varian ProStar preparative HPLC system equipped with a photo diode array (PDA) detector. LCMS was acquired on an Agilent 1100 LC system with PDA detector, coupled to a ThermoFinnigan LCQ-DECA ion trap mass spectrometer. ${ }^{1} \mathrm{H},{ }^{13} \mathrm{C}$, COSY, MEHSQC, HMBC and TOCSY experiments were performed on a Bruker Avance $500 \mathrm{MHz}$ spectrometer. NMR spectra were recorded in $\mathrm{MeOH}-d_{4}$ solutions, and the chemical shifts were referenced relative to the corresponding solvent signals $\left(\delta_{\mathrm{H}}=3.30\right.$ for ${ }^{1} \mathrm{H}$ NMR, $\delta_{\mathrm{C}}=49.1$ for $\left.{ }^{13} \mathrm{C} \mathrm{NMR}\right)$. High resolution mass spectral data were acquired on a Bruker-Daltonics Apex II Fourier transform mass spectrometer equipped with a BrukerMagnex 9.4 T superconducting magnet, and an Analytica electrospray source. The ESI source was operated in the nanoelectrospray mode. Typically, $5 \mu$ l sample was loaded into the nanoelectrospray tip (New Objective, Woburn, MA) and a high voltage of about $-700 \mathrm{~V}$ was applied between the tip and the glass capillary. Infrared spectra were recorded on a Nicolet Nexus 470 instrument in attenuated total reflectance (ATR) mode.

\section{Fermentation}

A seed medium of the following formulation was prepared by combining: dextrose (added after autoclaving), 1.0\%; soluble starch, 2.0\%; yeast extract, $0.5 \%$; N-Z amine type A (Sheffield), 0.5\%; calcium carbonate, $0.1 \%$; pH 7.0. Ten $\mathrm{ml}$ of seed medium in a $25 \times 150 \mathrm{~mm}$ glass tube was inoculated with two loopfuls of cell mass of LL-C31037 cultured on ATCC agar medium \#172. Sufficient inoculum from the agar culture was used to provide a turbid seed after 72 hours of growth. The primary seed tube was incubated for 72 hours at $28^{\circ} \mathrm{C}$, at $200 \mathrm{rpm}$ using a gyro- rotary shaker with a 2 -inch orbit. The primary seed $(7.0 \mathrm{ml})$ was then used to inoculate a $250-\mathrm{ml}$ Erlenmeyer flask containing $30 \mathrm{ml}$ of seed medium. This secondary seed flask was incubated for 24 hours at $28^{\circ} \mathrm{C}, 200 \mathrm{rpm}$ using a gyro-rotary shaker (2-inch orbit). Material from this seed fermentation was stored as a frozen stock in $10 \%$ glycerol and used as inoculum for the tank production medium (see below). A seed medium of the following formulation was prepared by combining: dextrose (added after autoclaving), $2.0 \%$; soluble starch, 2.0\%; yeast extract (Difco), $0.3 \%$; wheat hydrolysate WGE80M (DMV International), $0.5 \%$; soy hydrolysate SE50MAF (DMV International), 1.5\%; pH 6.8 to 7.0. One $\mathrm{ml}$ of frozen seed culture was inoculated into 1.0 liter of seed medium in a 4-liter Erlenmeyer flask. This seed flask was incubated for 72 hours at $30^{\circ} \mathrm{C}$ at $250 \mathrm{rpm}$ using a gyro-rotary shaker (2-inch orbit). A fermentation production medium of the following formulation was prepared by combining: dextrose (added after autoclaving), 2.0\%; maltrin M500, 8.0\%; nutrisoy (GPC), $1.0 \%$; yeast extract (Difco), $0.6 \%$; Gamaco $\left(\mathrm{CaCO}_{3}\right), 0.1 \%$; Macol P2000, 0.2\%; pH 6.8 to 7.0.

\section{Neuroprotective Activity}

Mesencephalic DAargic neuron cultures were prepared [8] and treated with compound. Cultures were then exposed to the neurotoxin $\mathrm{MPP}^{+}$, known to induce parkinsonism [9], and subsequent measurement of high-affinity ${ }^{3} \mathrm{H}$-dopamine uptake [10] provided a functional readout for putative neuroprotection of compounds that may be relevant to PD. For dopamine uptake experiments, single-cell suspensions in complete media were seeded on poly-L-ornithine and laminin coated 24-well plates. The cultures were maintained for seven days prior to experimentation. Cultures were pretreated with various concentrations of $\mathbf{1}$ for 24 hours, and then exposed to $10 \mu \mathrm{M}$ of the neurotoxin 1-methyl-4-phenylpyridinium $\left(\mathrm{MPP}^{+}\right)$for 1 hour to assess the neuroprotective effect of $\mathbf{1}$ in cell culture. Following the 
1-hour incubation, media was exchanged three times and fresh compound was added for an additional 48 hours. Cultures were washed with pre-warmed phosphate-buffered saline (PBS) containing $5.6 \mathrm{mM}$ glucose and $1 \mathrm{mM}$ ascorbic acid. Cultures were then incubated for 15 minutes at $37^{\circ} \mathrm{C}$ with $50 \mathrm{nM}{ }^{3} \mathrm{H}$-dopamine $(31 \mathrm{Ci} / \mathrm{mmol}$, Du PontNEN, Wilmington, DE, U.S.A.). The cultures were washed twice with buffer and lysed with $0.5 \mathrm{~N} \mathrm{NaOH}$. The lysate was transferred to a scintillation vial containing Ultima Gold scintillation cocktail and radioactivity was determined with a liquid scintillation counter.

\section{Results}

\section{Taxonomy of the Producing Organism}

Strain LL-C31037 was isolated from a soil sample collected in Eagle River, Wisconsin, USA in 1980. Cultures of Streptomyces sp. LL-C31037 on ATCC agar medium No. 172 display tan-colored substrate mycelia and produce neither aerial mycelium nor soluble pigment. The $16 \mathrm{~S}$ rDNA sequence was amplified and aligned to yield phylogenetic trees that supported classification of the strain in the genus Streptomyces. A viable culture of this microorganism has been deposited with the Northern Regional Research Laboratory (NRRL), U.S. Department of Agriculture, Peoria, IL 61604, and added to its permanent collection under accession number 30721 .

\section{Isolation}

Cells from 20 liters of culture of C31037 were pelleted by centrifugation. 5\% Diaion HP20 (Mitsubishi) in water was added to the supernatant, and this was stirred at room temperature overnight. The HP20 was washed with methanol and the filtrate collected. To the cell pellet, $80: 20$ ethyl acetate methanol was added. This was repeatedly shaken and centrifuged, and the supernatant collected. The cell supernatant and the broth methanol filtrate were combined and concentrated in vacuo. The crude extract was adsorbed onto silica $(32-63,60 \mathrm{~A})$, and run by VLC. The compound was eluted with $5 \%$ methanol in dichloromethane. This extract was concentrated in vacuo, adsorbed onto silica $(32-63,60 \mathrm{~A})$ and loaded onto a flash silica column $(60 \mathrm{~mm} \times 250 \mathrm{~mm})$. The compound was eluted with $2 \%$ methanol in dichloromethane. The extract was concentrated in vacuo and loaded onto Sephadex LH-20 $(60 \times 400 \mathrm{~mm}$, methanol). The column was initially washed with $300 \mathrm{ml}$ methanol and $30 \mathrm{ml}$ fractions were collected and monitored by LCMS. Early fractions which contained the compound of interest were collected and concentrated. This semi-pure material was chromatographed by preparative HPLC (YMC ODS-A $50 \times 250 \mathrm{~mm} 10 \mu$ column, A: water B: methanol, gradient: $55 \% \mathrm{~B}$ to $70 \% \mathrm{~B}$ in 200 minutes, $30 \mathrm{ml} /$ minute). 3 Normeridamycin was identified through LCMS analysis of fractions. These fractions of interest were pooled, concentrated in vacuo to afford pure 3-normeridamycin $\left(\mathrm{t}_{\mathrm{R}}=130\right.$ minutes, $\left.138 \mathrm{mg}\right)$.

\section{Physico-chemical Properties}

3-Normeridamycin (1) was obtained as an amorphous white solid; $[\alpha]_{\mathrm{D}}^{25}-1.1^{\circ}$ (c 1.0, $\left.\mathrm{MeOH}\right)$; UV $(\mathrm{MeOH})$ : end absorbance; IR (attenuated total reflectance) $v_{\max }: 3391,2931,1726,1677,1635,1449,1179,1132$, $800 \mathrm{~cm}^{-1}$; FT-ICRMS: $m / z=830.50021$ for $\mathrm{C}_{44} \mathrm{H}_{73} \mathrm{NO}_{12}$ $(\mathrm{M}+\mathrm{Na})^{+}$(calculated: 830.50305; $\left.\Delta \mathrm{mmu}=-2.8\right) ;{ }^{1} \mathrm{H}$ NMR $\left(500 \mathrm{MHz}, \mathrm{MeOH}-d_{4}\right)$ : see Table $1 ;{ }^{13} \mathrm{C}$ NMR $\left(125 \mathrm{MHz}, \mathrm{MeOH}-d_{4}\right)$ : see Table 1.

\section{Structure Elucidation}

The high resolution FT-ICR mass spectrum of $\mathbf{1}$ gave a molecular ion at $m / z=830.50021$ for the $(\mathrm{M}+\mathrm{Na})^{+}$adduct, yielding a molecular formula of $\mathrm{C}_{44} \mathrm{H}_{73} \mathrm{NO}_{12}$. Extensive analysis of the two-dimensional NMR spectral data for $\mathbf{1}$ confirmed the compound's identity. Structurally, $\mathbf{1}$ is related to the previously described non-immunosuppressive immunophilin ligand, meridamycin [11]. Although the NMR assignments of $\mathbf{1}$ were complicated by the two conformational populations observed due to cis-/transisomerization of the amide bond, as is the case for rapamycin [12], all resonances for the major conformer were assigned and are in good agreement with the literature assignments for meridamycin [11]. The presence of a proline residue in the macrocycle was confirmed by the observation of HMBC correlations from the ring carbons (C-3 to C-5) into 2-H, as well as correlations from C-1 into $3-\mathrm{H}_{2}$ and extensive COSY correlations between the proton resonances of the five-membered ring, (vide infra). The six olefinic carbons were identified from HSQC correlations, and from the ${ }^{13} \mathrm{C}$ spectrum. In particular, there is an HMBC correlation from a hydroxylated methine with proton at $\delta$ 3.75 into a quaternary olefinic carbon at $\delta$ 147.8. A methyl group at $\delta 1.05$ has an HMBC correlation into this olefinic carbon and a COSY correlation into a two methylene protons at $\delta 1.86$ and 2.34. These methylene protons also have HMBC correlation into the olefinic carbon at $\delta 147.8$.

Two methylene protons at $\delta 2.39$ and 2.62 also show correlations in the HMBC spectrum to the $\delta 147.8$ carbon. However, these methylene protons have HMBC and COSY correlations to the adjacent olefinic methine at $\delta 5.26$ securing its position on the other side of the double bond. This series of correlations confirms the presence of the 
Table $1{ }^{1} \mathrm{H}$ and ${ }^{13} \mathrm{C}$ Chemical shift assignments for 3normeridamycin $1\left(\mathrm{MeOH}-d_{4}, 500 \mathrm{MHz}\right)$

\begin{tabular}{|c|c|c|}
\hline Position & $\delta^{13} \mathrm{C}$ & $\delta^{1} \mathrm{H}$ (mult, $J \mathrm{~Hz}$ ) \\
\hline 1 & 171.8 & \\
\hline 2 & 59.9 & $4.44(\mathrm{dd}, 5.5,9.0)$ \\
\hline 3 & 30.2 & $1.92(\mathrm{~m}), 2.20(\mathrm{~m})$ \\
\hline 4 & 25.5 & $1.97(\mathrm{~m}), 2.00(\mathrm{~m})$ \\
\hline 5 & 48.2 & $3.48(\mathrm{~m}), 3.66(\mathrm{~m})$ \\
\hline 7 & 167.7 & \\
\hline 8 & 199.5 & \\
\hline 9 & 100.8 & \\
\hline 10 & 36.2 & 2.25 (m) \\
\hline 11 & 28.2 & $1.55(\mathrm{~m}), 1.68(\mathrm{~m})$ \\
\hline 12 & 33.4 & $1.42(\mathrm{~m}), 1.62(\mathrm{~m})$ \\
\hline 13 & 69.5 & $3.81(\mathrm{~m})$ \\
\hline 14 & 43.3 & 1.67 (m) \\
\hline 15 & 73.3 & 3.82 (m) \\
\hline 16 & 43.3 & $1.61(\mathrm{~m})$ \\
\hline 17 & 72.5 & $4.14(\mathrm{~m})$ \\
\hline 18 & 43.5 & $1.54(\mathrm{~m}), 1.70(\mathrm{~m})$ \\
\hline 19 & 68.1 & $3.89(\mathrm{~m})$ \\
\hline 20 & 44.0 & $1.53(\mathrm{~m}), 1.70(\mathrm{~m})$ \\
\hline 21 & 74.1 & $4.14(\mathrm{~m})$ \\
\hline 22 & 134.0 & \\
\hline 23 & 131.2 & $5.16(\mathrm{~m})$ \\
\hline 24 & 31.0 & $2.55(\mathrm{~m})$ \\
\hline 25 & 44.2 & $1.63(\mathrm{~m}), 1.73(\mathrm{~m})$ \\
\hline 26 & 36.7 & $1.54(\mathrm{~m})$ \\
\hline 27 & 80.4 & 3.75 (m) \\
\hline 28 & 147.8 & \\
\hline 29 & 120.3 & $5.26(\mathrm{~m})$ \\
\hline 30 & 31.7 & $2.39(\mathrm{~m}), 2.62(\mathrm{~m})$ \\
\hline 31 & 82.4 & $5.00(\mathrm{dd}, 5.6,9.0)$ \\
\hline 32 & 133.5 & \\
\hline 33 & 134.7 & $5.30(\mathrm{~m})$ \\
\hline 34 & 41.4 & 2.37 (m) \\
\hline 35 & 72.9 & 3.47 (m) \\
\hline 36 & 21.7 & $1.11(\mathrm{~m})$ \\
\hline 37 & 17.3 & 1.00 (m) \\
\hline 38 & 13.0 & $1.70(d, 0.91)$ \\
\hline 39 & 15.5 & $0.85(\mathrm{~m})$ \\
\hline 40 & 12.2 & $0.94(\mathrm{~m})$ \\
\hline 41 & 13.6 & 1.66 (m) \\
\hline 42 & 22.7 & $0.96(\mathrm{~m})$ \\
\hline 43 & 14.5 & $0.87(\mathrm{~m})$ \\
\hline 44 & 23.6 & $1.86(\mathrm{~m}), 2.34(\mathrm{~m})$ \\
\hline 45 & 14.3 & $1.05(\mathrm{~m})$ \\
\hline
\end{tabular}

allylic ethyl group $\left(44-\mathrm{H}_{2}\right.$ and $\left.45-\mathrm{H}_{3}\right)$ at $\mathrm{C}-28$, therefore ruling out the possibility of an allylic methyl at this position (to account for the formal deficit of 14 mass units relative to meridamycin).

The macrolactone linkage was confirmed via the observation of HMBC correlations from both the H-31 methine proton at $\delta 5.00$ and from the $\mathrm{H}-2$ methine proton at $\delta 4.44$ to the ester carbonyl (C-1) at 171.8. Moreover, the chemical shift of this proton (H-2) is consistent with an amino acid $\alpha$-proton. There are additional HMBC correlations from $3-\mathrm{H}_{2}$ to the $\delta 171.8$ carbonyl. Subsequent analysis of COSY correlations and HMBC correlations around and across the ring confirm the presence of only two additional methylenes $\left(4-\mathrm{H}_{2}\right.$ and $\left.5-\mathrm{H}_{2}\right)$, indicating that the ring is a 5 -membered proline, not the 6-membered pipecolic acid. The important COSY and HMBC correlations herein described are diagrammed in Figure 2.

Extensive overlap in both the ${ }^{1} \mathrm{H}$ and ${ }^{13} \mathrm{C}$ NMR spectra of 1, particularly in the $\mathrm{C}-15$ to $\mathrm{C}-21$ region, precluded the possibility of using $J$-configuration analysis [13] to assign the relative stereochemistry of $\mathbf{1}$. The absolute stereochemistry of meridamycin has been reported [14], and while it is biosynthetically logical to assume an identical configuration for $\mathbf{1}$, experiments are underway to obtain a crystalline sample of $\mathbf{1}$ for X-ray diffraction analysis.

\section{Biological Activity}

3-Normeridamycin (1) exhibited potent restoration of dopamine uptake in $\mathrm{MPP}^{+}$challenged neurons, with statistical significance down to low nanomolar concentrations [15]. Relative to a maximum recovery obtained using the growth factor GDNF, $\mathrm{EC}_{50}$ of all compounds are given in Table 2. The biological activity of $\mathbf{1}$ stands in marked contrast to the related natural product immunophilin ligands FK506 [16] and rapamycin [17]. Whereas 1 is nonimmunosuppressive, as measured in a human mixed lymphocyte reaction (MLR) [18], both $\mathbf{2}$ and $\mathbf{3}$ are potent inhibitors of immune response, though by different mechanisms [3]. FKBP12 binding was measured per standard procedure [19].

\section{Discussion}

3-Normeridamycin is closely related to the non-immunosuppressive macrolide meridamycin, isolated from $S$. hygroscopicus. Meridamycin, in contrast to the macrolides FK506 and rapamycin, is one of only two nonimmunosuppressive natural product immunophilin ligands in this structural class. Previous work on rapamycin has shown that the pipecolate incorporating enzyme can accommodate a number of substrate analogs [20], in particular proline to produce a proline containing nor- 


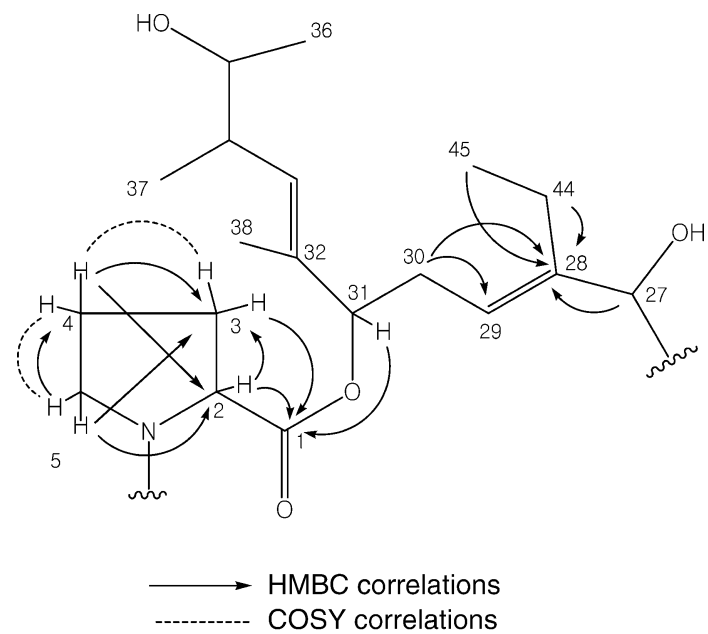

Fig. 2. 3-Normeridamycin selected $2 D$ NMR correlations.

rapamycin [21]. The occurrence of a naturally occurring normeridamycin is therefore in agreement with literature precedent, suggesting that the biosynthetic pathway of meridamycins may be similar to that of rapamycin and FK506 [22].

Meridamycin is known to inhibit binding of FK506 to FKBP12, and to antagonize immunosuppression in FK506 and rapamycin. 3-Normeridamycin is also nonimmunosuppressive and exhibits potent neuroprotective activity against the neurotoxin $\mathrm{MPP}^{+}$. In particular, it was found to have low nanomolar activity in restoring dopamine uptake in $\mathrm{MPP}^{+}$treated neurons. Based on these findings, 3-normeridamycin shows potential utility as a therapeutic agent in the treatment of Parkinson's disease.

In conclusion, we herein report the isolation and characterization of a new neuroprotective nonimmunosuppressive immunophilin ligand, 3-normeridamycin (1). The compound exerts a profound neuroprotective effect in DAergic neurons after challenge with $\mathrm{MPP}^{+}$, thus representing a potential new lead for therapeutic applications in the treatment of Parkinson's disease.

Acknowledgment We thank Ker Yu for FKBP12 binding data, Beatriz Carreno for obtaining immunosuppression data, Valerie Bernan for taxonomy and 16S rDNA analysis, Xidong Feng for obtaining FT-ICRMS data, Thomas Williamson for obtaining NMR spectral data, and Gow-Jen Tsai for providing large-scale fermentations of LL-C31037.

\section{References}

1. Horn S, Stern MB. The comparative effects of medical therapies for Parkinson's disease. Neurology 63: S7-12 (2004)
Table 2 Neuroprotective activities of compounds $\mathbf{1} \sim \mathbf{3}$

\begin{tabular}{crcc}
\hline Compound & $\begin{array}{c}{ }^{3} \text { H DA uptake } \\
\mathrm{EC}_{50}(\mathrm{nM})\end{array}$ & $\begin{array}{c}\mathrm{FKBP} 12 \text { binding } \\
\mathrm{ED}_{50}(\mathrm{nM})\end{array}$ & $\begin{array}{c}\mathrm{MLR} \\
\mathrm{IC}_{50}(\mathrm{nM})\end{array}$ \\
\hline $\mathbf{1}$ & 110 & 50 & $>10000$ \\
$\mathbf{2}$ & $>10000$ & 0.2 & 1.1 \\
$\mathbf{3}$ & 49 & $0.4^{\mathrm{a}}$ & $0.22^{\mathrm{a}}$ \\
\hline
\end{tabular}

a Data taken from reference 16.

2. LeWitt PA. Clinical trials of neuroprotection for Parkinson's disease. Neurology 63: S23-31 (2004)

3. For reviews see: a) Schreiber SL, Albers MW, Brown EJ, The cell cycle, signal transduction, and immunophilin-ligand complexes. Acc Chem Res 26: 412-420 (1993)

b) Ivery MTG. Immunophilins: Switched on protein binding domains? Med Res Rev 20: 452-484 (2000)

c) Mann J. Natural products as immunosuppressive agents. Nat Prod Rep 18: 417-430 (2001)

4. Lyons WE, Steiner JP, Snyder SH, Dawson TM. Neuronal regeneration enhances the expression of the immunophilin FKBP- 12 J. Neurosci 15: 2985-2994 (1995)

5. Steiner JP, Connolly MA, Valentine HL, Hamilton GS, Dawson TM, Hester L, Snyder SH. Neurotrophic actions of nonimmunosuppressive analogues of immunosuppressive drugs FK506, rapamycin and cyclosporin A. Nature Medicine 3: 421-428 (1997)

6. For a review see: Pong K, Zaleska MM. Therapeutic implications for immunophilin ligands in the treatment of neurodegenerative diseases. Curr Drug Tar CNS Neurol Dis 2: 349-356 (2003)

7. See for example: a) Gold BG, Armistead DM, Wang MS. Non-FK506-binding protein-12 neuroimmunophilin ligands increase neurite elongation and accelerate nerve regeneration. J Neurosci Res 80: 56-65 (2005)

b) Gold BG, Densmore V, Shou W, Matzuk MM, Gordon HS. Immunophilin FK506-binding protein 52 (not FK506binding protein 12) mediates the neurotrophic action of FK506. J Pharmacol Exp Ther 289: 1202-1210 (1999)

8. Pong K, Doctrow SR, Baudry M. Prevention of 1-methyl-4phenylpyridinium- and 6-hydroxydopamine-induced nitration of tyrosine hydroxylase and neurotoxicity by EUK-134, a superoxide dismutase and catalase mimetic, in cultured dopaminergic neurons. Brain Res 881: 182-189 (2000)

9. Speciale SG. MPTP: Insights into parkinsonian neurodegeneration. Neurotox Teratol 24: 607-620 (2002)

10. Prochiantz A, Daguet MC, Herbet A, Glowinski J. Specific stimulation of in vitro maturation of mesencephalic dopaminergic neurons by striatal membranes. Nature 293: 570-572 (1981)

11. Salituro GM, Zink DL, Dahl A, Nielsen J, Wu E, Huang L, Kastner C, Dumont FJ. Meridamycin: a novel nonimmunosuppressive FKBP12 ligand from Streptomyces hygroscopicus. Tetrahedron Lett 36: 997-1000 (1995) 
12. a) Kessler H, Haessner R, Schüler W. Structure of rapamycin: an NMR and molecular-dynamics investigation. Helv Chim Acta 76: 117-130 (1993)

b) McAlpine JB, Swanson SJ, Jackson M, Whittern DN. Revised NMR assignments for rapamycin. J Antibiot 44: 688-690 (1991)

13. a) Murata M, Matsuoka S, Matsumori N, Paul GP, Tachibana K. Absolute configuration of amphidinol 3, the first complete structure determination from amphidinol homologues: application of a new configuration analysis based on carbon-hydrogen spin-coupling constants. J Am Chem Soc 121: 870-871 (1999)

b) Matsumori N, Kaneno D, Murata M, Nakamura H, Tachibana K. Stereochemical determination of acyclic structures based on carbon-proton spin-coupling constants. A method of configuration analysis for natural products. J Org Chem 64: 866-876 (1999)

14. Fehr T, Sanglier T, Schuler W. (Sandoz Ltd.). Rapamycinlike macrolide and a new strain of Streptomyces which produces it. WO9418207, August 18 (1994)

15. a) Graziani EI, Pong K. (Wyeth). Non-immunosuppressive immunophilin ligands as neuroprotective and/or neuroregenerative agents. US2005197356A1, September 8 (2005)

b) Summers MHY, Graziani EI, Leighton MM, Pong K, Kele RA. (Wyeth). Macrolides and methods for producing same. US2005197379A1, September 8 (2005).

16. Kino T, Hatanaka H, Miyata S, Inamura N, Nishiyama M,
Yajima T, Goto T, Okuhara M, Kohsaka M, Aoki H. FK-506, a novel immunosuppressant isolated from a Streptomyces. II. Immunosuppressive effect of FK-506 in vitro. J Antibiot 40: 1256-1265 (1987)

17. Abraham RT. Mammalian target of rapamycin: immunosuppressive drugs uncover a novel pathway of cytokine receptor signaling. Curr Opin Immunol 10: 330-336 (1998)

18. $\mathrm{Xu} \mathrm{H,} \mathrm{Montgomery} \mathrm{SP,} \mathrm{Preston} \mathrm{EH,} \mathrm{Tadaki} \mathrm{DK,} \mathrm{Hale} \mathrm{DA,}$ Harlan DM, Kirk AD. Studies investigating pretransplant donor-specific blood transfusion, rapamycin, and the CD154-specific antibody IDEC-131 in a nonhuman primate model of skin allotransplantation. J Immunol 170: 2776-2782 (2003)

19. Ritacco FV, Graziani EI, Summers MY, Zabriskie TM, Yu K, Bernan VS, Carter GT, Greenstein M. Production of novel rapamycin analogs by precursor-directed biosynthesis. Appl Envir Microbiol 71: 1971-1976 (2005)

20. Graziani EI, Ritacco FV, Summers MY, Zabriskie TM, Yu K, Bernan VS, Greenstein M, Carter GT. Novel sulfur-containing rapamycin analogs by precursor-directed biosynthesis. Org Lett 5: 2385-2388 (2003)

21. Russo RJ, Howell SR, Sehgal SN. (AHP) 21-Norrapamycin. U.S. 5,441,977, August 15 (1995)

22. He M, Hucul J, Haltli BA, Wagenaar MM, Graziani E, Summers M, Kulowski K, Pong K. (Wyeth) Biosynthetic gene cluster for the production of a complex polyketide. US20050272133A1, December 8 (2005) 